\title{
Contributions of HLA haplotypes, IL8 level and Toxoplasma gondii infection in defining celiac disease's phenotypes
}

Mohammad Rostami-Nejad', Seyed Hossein Hejazi ${ }^{2}$, Amado Salvador Peña ${ }^{3}$, Hamid Asadzadeh-Aghdaei ${ }^{4}$, Kamran Rostami ${ }^{5^{*}}$, Umberto Volta ${ }^{6}$ and Mohammad Reza Zali ${ }^{1}$

\begin{abstract}
Background: It is not clear why some patients with coeliac disease (CD) present with severe symptoms and small intestinal mucosal damages while others present with milder symptoms and no frank enteropathy. There is no study to assess the associated factors with mild/severe symptoms and enteropathy. The terminologies like latent, silent and potential are difficult to use and are unrepresentative. In the present study we describe coeliac disease's phenotypes based on HLA haplotypes, IL8 production and past infection with Toxoplasma gondii (T. gondii) infection.
\end{abstract}

Methods: In this case-control study, sera originating from 150 healthy subjects and 150 patients diagnosed with CD during the years 2013-14 were analyzed for the presence of antibodies specific T. gondii of the IgG and IgM subclasses. The level of IL8 were measured and HLA-DQ2 and HLA-DQ8 alleles were genotyped. The correlation between these parameters and the damages in intestinal mucosal were assessed using an accepted histopathological classification.

Results: High levels of IgG antibodies against $T$. gondii were found in the sera of control group compared to the CD group (52.6\% vs. $39.4 \%, P=0.02)$. Mean serum levels of IL8 was significantly higher in CD patients compared with control $(P \leq 0.05)$. By comparing the level of anti- T. gondii lgG and mucosal damage in celiac disease, we found a significant relationship between the severity of mucosal damages and anti- T. gondii lgG level $(P=0.02)$. No correlation was detected between Toxoplasma gondii infection and types of HLA $(P>0.05)$. However, patients with severely abnormal histology carried HLA-DQ2 risk alleles (92 patients (61\%)) more often than the controls and those with mild histological abnormalities.

Conclusions: CD patients with severe histological changes had more often Toxoplasma gondii infection than those affected with mild histological features. This suggests that CD's phenotypes are correlated to additional factors like infections and to particular HLA DQ2 alleles that may need additional investigations and potentially will require additional treatment.

Keywords: Celiac disease, Toxoplasmosis, Antibodies, HLA alleles, Histological features, Gluten

\footnotetext{
* Correspondence: krostami@hotmail.com

${ }^{5}$ Department of Gastroenterology, Milton Keynes University Hospital, Milton Keynes, UK

Full list of author information is available at the end of the article
}

(c) The Author(s). 2018 Open Access This article is distributed under the terms of the Creative Commons Attribution 4.0 International License (http://creativecommons.org/licenses/by/4.0/), which permits unrestricted use, distribution, and reproduction in any medium, provided you give appropriate credit to the original author(s) and the source, provide a link to the Creative Commons license, and indicate if changes were made. The Creative Commons Public Domain Dedication waiver (http://creativecommons.org/publicdomain/zero/1.0/) applies to the data made available in this article, unless otherwise stated. 


\section{Background}

The spectrum of histological abnormalities in $\mathrm{CD}$ ranges from mild to severe mucosal changes however, the correlation with the symptoms of the patients is poor $[1,2]$. The classical presentation is becoming extremely rare and the majority of the patients have an atypical presentation [1]. The terminology used in the classification of $\mathrm{CD}$, like silent, potential and latent, fails to distinguish effectively between atypical forms of this condition and often leads to the confusion of the clinicians [2]. Subsequently many patients are left in uncertainty without treatment. The differences in small bowel permeability, caused by different degrees of mucosal abnormalities leading to a variety of intestinal or extraintestinal symptoms, result in different disease phenotypes. The innate and adoptive immunities by inflammatory and proinflammatory cytokines like IL1, IL6, IL8, and IL17 induce the inflammation in the small bowel mucosa that leading to mild to severe malabsorption syndrome [3].

More than $90 \%$ of celiac disease patients were HLADQ2 positive [4]. CD may affect patients at any age, and the intestinal lesions may be accompanied by abnormalities in other organs with manifestations or complications, including brain, mood and reproductive organs [5]. The factors associated with these associations have not been studied adequately. How far gluten is involved in the pathogenesis of neurological disorders such as autism, schizophrenia, mental retardation and bipolar disorder is not elucidated [5-7]. In contrast to other autoimmune conditions, where the trigger of the disease is not known, [8] the strict removal of the gluten of the diet reverts the small intestinal abnormalities to normal and it is effective in treatment of some associated conditions such as dermatitis herpetiformis and some of the patients with gluten ataxia. The lack of correlation between the symptoms and histological changes induces the searching of other factors to understand the clinical significance and the pathogenesis of the disease.

According to the result of animal studies, as soon as Toxoplasma gondii invades the epithelial cells of the small intestine a severe form of intestinal inflammation is induced [9-11].

In the small intestine, Toxoplasma gondii infection may initiate the sequence of innate immunologic reactions that usually result in a vigorous inflammatory process [11]. In the mice model, the immune reaction result in morphologic and histologic characteristics similar to human intestinal autoimmune disorders such as celiac disease and inflammatory bowel disease like destruction of intestinal epithelial cells, shortened villi, substantial invasion of inflammatory cells into the lamina propria and an increase number of intraepithelial lymphocytes (IELs) [12].
In addition to environmental factors such as infectious agents and diet and immunological issues like cytokines, genetic influence mostly by the human leukocyte antigens HLA DQ2 and DQ8 are necessary for CD development. We hypotheses that the combination of $T$. gondii infection, HLA predisposition and inflammatory cytokines like IL8 may contribute in histological abnormality and their presence may introduce as representative marker of mucosal severity of celiac disease patients.

Therefore, the aim of this study was to evaluate the role of the presence of Toxoplasma gondii previous infection, HLA alleles, and IL8 level at the time of presentation in the severity of the mucosal damage and their possible impact on CD phenotype.

\section{Methods}

Patients

One hundred and fifty untreated celiac disease patients with serum anti-human tissue Transglutaminase (tTG) IgA positive test and histopathological evidence according to the Marsh classification were randomly enrolled following referral to the celiac disease department unit of Research Institute for Gastroenterology and Liver Diseases, Shahid Beheshti University of Medical Sciences, Tehran, Iran during the 2012-2014. The 150 healthy subjects without CD matched by age were selected from referred cases to Taleghani hospital's lab for routine blood test.

A questionnaire covering demographic data, patients' symptoms and medication used was filled in. Four biopsies were taken from the second portion of the duodenum, one from bulb and one from D3 [13] oriented on filter paper, fixed overnight in buffered formalin, embedded in paraffin, cut to $3-\mu \mathrm{m}$ thickness, and stained with hematoxylin-eosin for routine histological evaluation.

The Hematoxylin and Eosin (H\&E) slides were reviewed by expert pathologists and histopathological findings were evaluated in according to the most recently revised Marsh classification [12] as presented and accepted during the International celiac disease congress, Prague 2015 [14].

Informed consent was obtained from each patient prior to study enrollment. The study was approved by ethics review board of Gastroenterology and Liver Diseases Research Center, Shahid Beheshti University of Medical Sciences, Tehran, Iran (IR.SBMU.RIGLD.1395.90).

\section{Blood sample collection}

Ten milliliters of venous blood was drawn for both specific celiac disease antibodies and Toxoplasma gondii antibodies and sera were separated and kept at $-70{ }^{\circ} \mathrm{C}$. tTG-IgA antibody was measured using a commercially available ELISA kit (AESKULISA tTGA, Germany) according to the manufacturer's guidelines and the result was considered positive when a value higher than $15.0 \mathrm{U} / \mathrm{ml}$ was recorded. Total 
serum IgA values were measured by an immunoturbidometric assay (Pars Azmoon, Iran) and according to manufacturer's guideline, serum levels below $70 \mathrm{U} / \mathrm{L}$ were considered indicative of IgA deficiency.

Immunoglobulin G (IgG) tTG values were further obtained in individuals with IgA deficiency by an ELISA method, and using the commercially available kit AESKULISA tTGG (Germany).

In addition, the Toxoplasma specific IgG and specific IgM antibodies in the same serum samples were assayed by commercial ELISA kit (ELISA, Vircell Toxoplasma IgG\&IgM/Spain) according to the manufacturer's instruction. In keeping with the manufacturer's guidelines, a result was considered positive when a value higher than $1: 10 \mathrm{IU} / \mathrm{ml}$ was recorded.

IL8 level was measured according to the manufacturer's instruction in both groups by commercial Enzyme Linked Immunosorbant Assay kit (Human IL8/NAP-1 ELISA, Bender MedSystems, Austria).

We considered a diagnosis of $\mathrm{CD}$ if the patients had high levels of IgA anti-tTG $>3$ times of upper normal limit and confirmed by appropriate histology and HLA typing. For instance in patients with a phenotype of Marsh I-II, the diagnosis was confirmed as potential celiac disease (PCD) by HLA typing and high titers of IgA anti-tTG, 3 times higher than cut off or positive at any titer, but confirmed by IgA EMA positivity.

\section{HLA typing}

For HLA typing genomic DNA was extracted using salting out method and HLA-DQ2/HLA-DQ8 haplotypes were genotyped by Real-time PCR using SYBR Green as described [15]. In brief, HLA-DQB1*02 was determined for HLA-DQ2, HLADQB1* 02 and HLA-DQA1*05 for HLA-DQ2.5 and HLA-DQB1*0302 for HLA-DQ 8.

\section{Statistical analysis}

Percentages were compared by rates and proportion; 95\% confidence intervals are reported. We also used the corrected $x^{2}$ test or Fisher's exact test and odds ratio to compare percentages, and the unpaired Student t-test to compare the means of normally distributed variables. Tukey's Multiple Comparison Test and Multivariate logistic regression analysis was performed to analysis the difference between groups.

\section{Results}

One hundred and fifty subjects with CD (mean age \pm $\mathrm{SD}=34.9 \pm 13.68)$ were recruited as case and 150 individuals (mean age $\pm \mathrm{SD}=34.1 \pm 13.95$ ) as control. No statistically significant differences were noted between the groups regarding demographic characteristics. The main symptoms of celiac disease at the time of diagnosis was diarrhea [45/150 cases (30\%)], anemia [26/150 subjects (17.3\%) and epigastric pain [22/150 individuals (14.7\%)] respectively. Between the extra intestinal presentations menarche disturbances (4.4\%) and abortion (6\%) were low prevalent. In patients with Marsh I, 22 (73\%), presented with weight loss, 20 (67\%) with neurological disorders and bloating/osteopenia in 16 (53.3\%) and in patients with Marsh II, bloating 23 (65.7\%), osteopenia/neurological disorders 21 (60\%), and weight loss $20(57.1 \%)$ were found most prevalent. Similarly in patients with Marsh III, weight loss [63 (74.1\%)], bloating [58 (68.2\%)] and osteopenia in 55 (64.7\%) were recorded. Statistical analysis revealed no significant relationship between histology and gastrointestinal symptoms among celiac disease patients (Table 1).

Fifty nine (39.4\%) of patients with CD and 79 (52.6\%) of controls, had positive total IgG for Toxoplasma gondii. On the other hand, only $0.6 \%$ of cases (1 case) and $1.4 \%$ of controls ( 2 subjects) were serologically positive for anti-Toxoplasma IgM. There were statistical significant differences between the cases and control regarding total $\operatorname{IgG}$ level $(P=0.02)$. There was no significant relationship between age, marital status, employment status, ethnicity, educational status, smoking, history of breast-feeding in infancy and anti-T. Toxoplasma gondii IgG in celiac patients compare to controls $(P>0.05)$. Also no significant associations were observed between type of meat consumption, cat keeping and traveling and infection with anti- Toxoplasma gondii IgG in two groups $(P>0.05)$.

No statistically significant differences were noted for distribution of either CD or Toxoplasma gondii positive patients between different ethnic groups. Compared to anti- Toxoplasma gondii IgG negative patients, the level

Table 1 Relationship between Marsh classification and gastrointestinal symptoms and signs in patients with celiac disease

\begin{tabular}{lllll}
\hline $\begin{array}{lllll}\text { Patient's symptoms } \\
\text { and signs }\end{array}$ & \multicolumn{3}{l}{ Marsh classification (\%) } & P value \\
\cline { 2 - 4 } & Marsh I & Marsh II & Marsh III & \\
\hline Diarrhea & $9(30)$ & $8(22)$ & $30(35.9)$ & 0.39 \\
Nausea and vomiting & $10(34)$ & $14(40)$ & $29(34.1)$ & 0.8 \\
Weight loss & $22(73)$ & $20(57.1)$ & $63(74.1)$ & 0.16 \\
Heart burn & $15(50)$ & $21(60)$ & $52(61.1)$ & 0.55 \\
Bloating & $16(53.3)$ & $23(65.7)$ & $58(68.2)$ & 0.34 \\
Anemia & $5(17)$ & $12(34.3)$ & $24(28.2)$ & 0.24 \\
Osteopenia & $16(53.3)$ & $21(60)$ & $55(64.7)$ & 0.65 \\
Neurological signs & $20(67)$ & $21(60)$ & $51(60)$ & 0.79 \\
Menarche problem & 0 & $1(2.9)$ & 0 & 0.58 \\
Infertility & 0 & 0 & $2(2.3)$ & 0.64 \\
Abortion & $1(3.4)$ & $2(5.7)$ & $6(7)$ & 0.7 \\
Aphthous stomatitis & $2(6.6)$ & $3(8.6)$ & $16(8.8)$ & 0.22 \\
\hline
\end{tabular}


of anti-Toxoplasma gondii IgG in patients with bloating was slightly higher (Table 2).

Both Toxoplasma gondii infection and celiac disease are reported to be associated with abortion. In our cohort, 3 out of 9 celiac subjects who had a history of abortion had positive IgG for Toxoplasma gondii. Also there was no correlation between symptoms and Toxoplasma gondii infection in coeliac patient $(P>0.05)$.

By comparing the level of anti-Toxoplasma gondii IgG and mucosal damage in celiac disease, we found a significant relationship between the severity of mucosal damages and a positive anti-Toxoplasma gondii IgG $(P=0.02)$. Patients with severe mucosal damage such as Marsh III had higher antibody levels than patients with less severe mucosal damage such as Marsh I and II. There was a significant correlation $(P=0.05)$ between positive and negative levels of IgG and mucosal damages as illustrated in Fig. 1.

Serum IL8 levels were evaluated in patients with CD compared with healthy control and the results showed that mean serum levels of IL8 was significantly higher in CD patients (mean serum level $\pm \mathrm{SD}=176.4 \pm 191.8$ ) compared with control (mean serum level $\pm \mathrm{SD}=68.87 \pm 86.8$ ) $(p=0.001)$. There is statistically significant differences between the average level of IL8 in 59 patients with CD and 79 healthy subjects who were positive for antiToxoplasma gondii IgG [170.2 ( $\mathrm{SD}=186.66)$ vs. 66.53 $(\mathrm{SD}=87 / 88)]$ respectively $(P=0.002)$. But no significant relationship were observed between the level of mucosal damage and IL8 levels in CD patients $(p=0.97)$. Also the level of IL8 in coeliacs with and without Toxoplasma gondii infection was not statistically significant $(P=0.09)$.

Table 2 Relationship between anti-Toxoplasma lgG and gastrointestinal symptoms and signs in celiac disease

\begin{tabular}{llll}
\hline $\begin{array}{l}\text { Patient's symptoms } \\
\text { and signs }\end{array}$ & \multicolumn{1}{l}{$\mathrm{lg}$} & \\
\cline { 2 - 3 } & Positive (\%) & Negative (\%) & $P$ value \\
\hline Diarrhea & $19(32.2)$ & $28(30.8)$ & 0.859 \\
Nausea and vomiting & $18(30.5)$ & $35(38.5)$ & 0.383 \\
Weight loss & $41(69.5)$ & $64(70.3)$ & 1 \\
Heart burn & $30(50.8)$ & $58(63.7)$ & 0.129 \\
Bloating & $40(67.8)$ & $18(30.5)$ & 0.6 \\
Anemia & $18(30.5)$ & $23(25.3)$ & 0.346 \\
Osteopenia & $33(55.9)$ & $59(64.8)$ & 0.543 \\
Neurological signs & $36(61)$ & $56(61.5)$ & 1 \\
Menarche disturbances & 0 & $4(4.4)$ & 0.154 \\
Infertility & $6(4)$ & $10(6.7)$ & 0.332 \\
Abortion & $3(5.11)$ & $6(6.6)$ & 0.476 \\
Aphthous stomatitis & $11(18.6)$ & $10(11)$ & 0.233 \\
\hline
\end{tabular}

On the other hand the results showed that in $\mathrm{CD}$ patients $77.3 \%$ were DQ2 positive, $20 \%$ DQ8 positive and $2.7 \%$ were negative for both haplotypes. Of these 4 HLA negative patients 2 were Marsh II and 2 Marsh III but all were positive for anti-tTG IgA and anti-EMA IgA with titer 3 times higher than the cut off. For the control group 31.3 and $10 \%$ were DQ2 and DQ8 positive respectively and $58.7 \%$ were DQ2/8 negative. In the cases 54 patients with Marsh I and II (23 patients with Marsh I and 31 with Marsh II) compared to 92 patients with Marsh III were carried the HLA-DQ2/8 haplotypes but no statistically significant difference was detected between HLA typing and severity of histology $(P=0.68)$. In addition there was no correlation between anti-Toxoplasma IgG and HLA typing in either cases or controls $(P>0.05)$. Multivariate logistic regression analysis showed that there is no association between the combination of $T$. gondii infection, HLA predisposition, and IL8 level and mucosal abnormality in CD patients $(p=0.17)$.

\section{Discussion}

Atypical presentation makes the diagnosis of celiac disease very challenging. Although terminologies like latent, silent and potential have been useful in research leading to identify the behavior of some atypical cases with $C D$, but in clinical practice not only they didn't simplify the recognition of atypical forms of disease, also contributed to more confusion between both clinicians and patients. By using these terminologies, it is difficult to reach a meaningful diagnosis and clear guide to treatment. The heterogeneity of presentation of $\mathrm{CD}$ requires a better classification that would satisfy patients and clinician's need for an effective diagnosis and a clear guide to management. The cases in this study have been identified using their generic phenotypes.

The question that hasn't been answered in the current literature is why some patients present with milder histology and others with more severe form of mucosal abnormalities and yet there is no correlation between histology, malabsorption syndrome and symptoms. In this study we have identified some factors that may correlate and explain the variability in presentation of CD. Immune intolerance in celiac disease is connected to genetic (types of genes on chromosomes 5,6 , and 19), and environmental factors such as viral, bacterial or parasitic infections and food antigens. These factors in combination may cause more severe tissue inflammation following losing the tolerance to gluten [16]. See Additional file 1. Review of published relevant studies indicate that infectious agents can contribute to the development of $\mathrm{CD}$ in susceptible individuals [17].

In several studies, an association has been found between celiac disease and infections like hepatitis C 


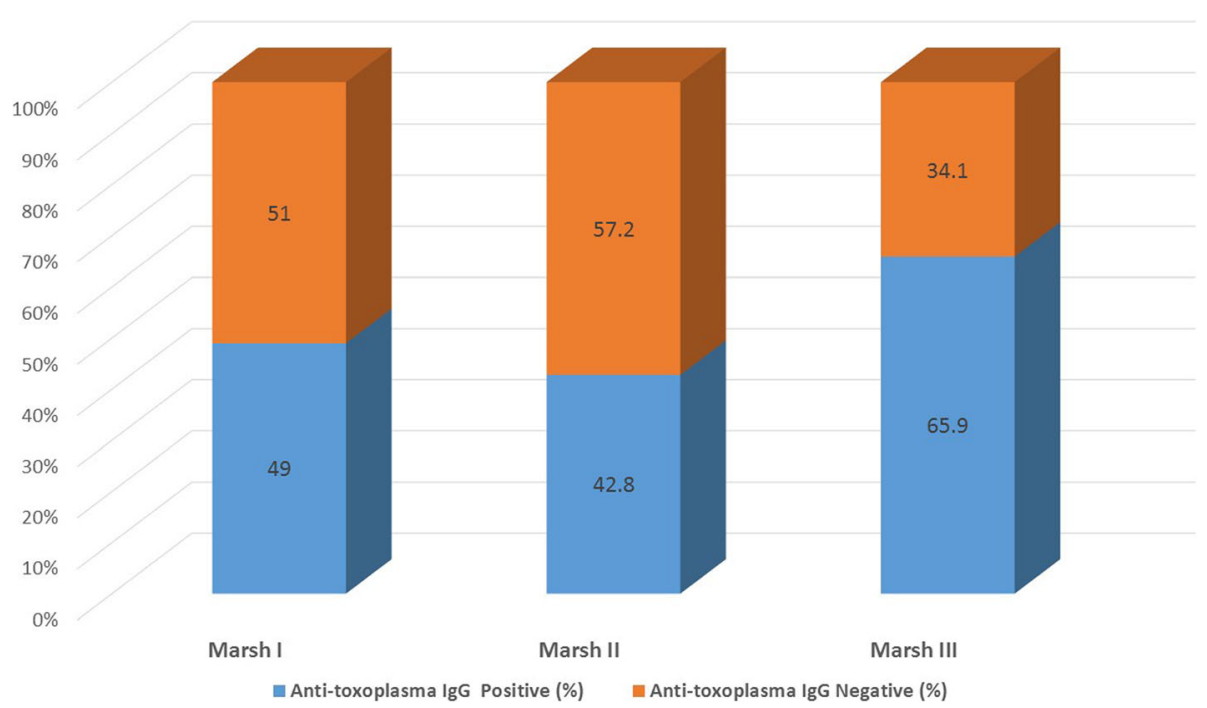

Fig. 1 The Relationship between positive and negative levels of IgG anti-Toxoplasma and mucosal damage according to Marsh classification. This differences for Marsh III is statistically significant ( $P$ Value $=0.02)$

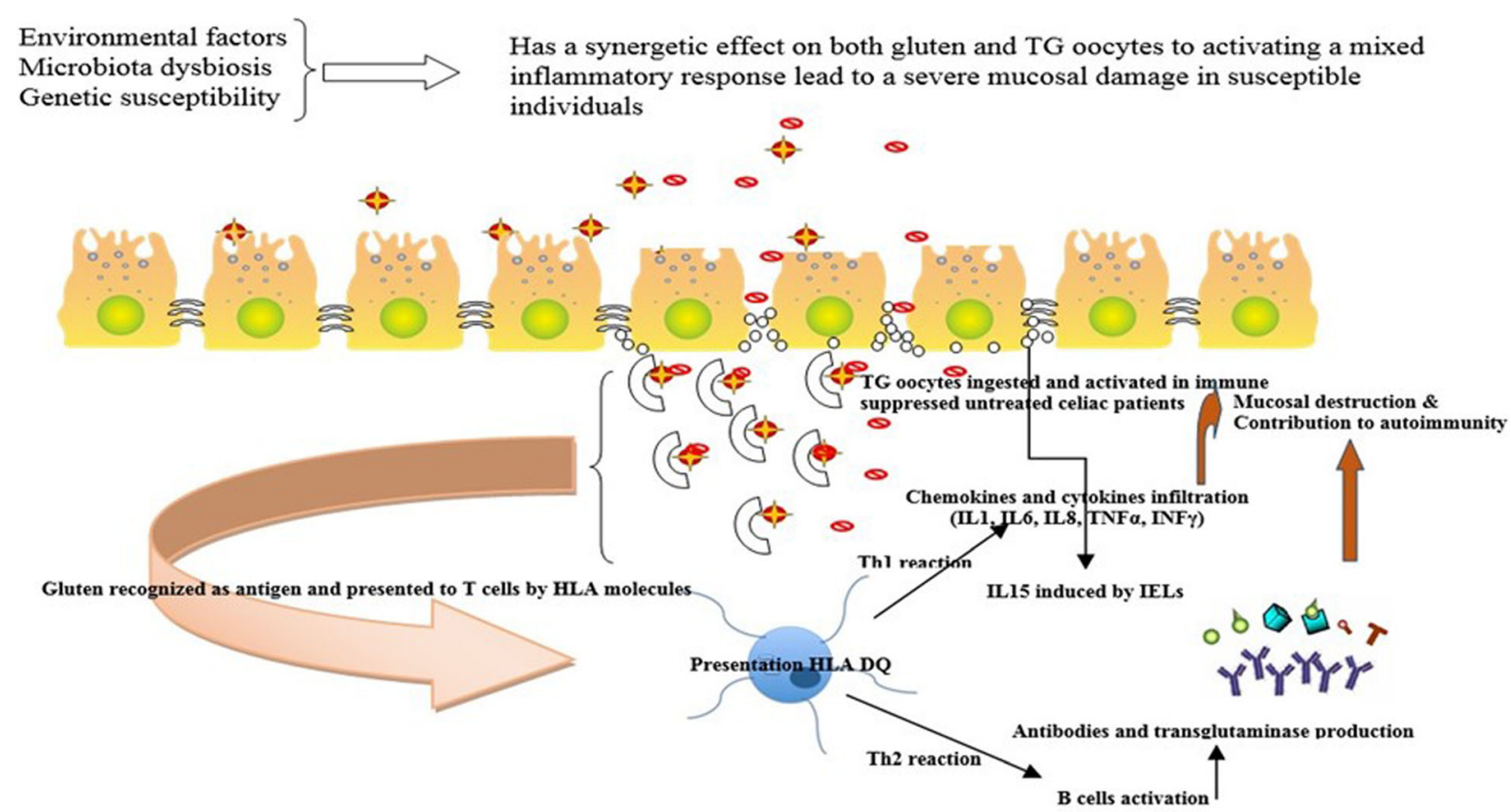

\begin{tabular}{|c|l|}
\hline$\theta$ & Toxoplasma gondii (TG) oocyte \\
\hline$\phi$ & Gluten \\
\hline$B$ & Tissue transglutaminase \\
\hline$\bullet$ & dendritic cell \\
\hline rymir & Antibodies and transglutaminase \\
\hline$\circ$ & Intraepithelial Lymphocytes \\
\hline
\end{tabular}

Fig. 2 T. gondii oocytes are released, penetrating the intestinal epithelium in patients with mild intestinal inflammation caused by gluten. Both are presented to the APC (HLA) and stimulate a Th1 response such as abundant amounts of cytokines such as IL1, IL6, IL8, TNFa and INFF, neutrophlis, macrophages as well as a Th2 response with production of antibodies against tTG2 and finally activate the adaptative immune response and facilitate the destruction of the villi. Ingested T. gondii oocysts probably increase the tissue damage of suffering from celiac disease 
virus, adenovirus, [16, 17] rotavirus and reovirus [18]. The parasitic infectious agents such as Giardia lamblia had been described in several case reports [19]. It looks like the activation of other part of immune system may lead to a more severe mucosal damages and possible additional symptoms in only some cases. For instance in response to parasitic infection, Dendritic Cells (DCs), PMNs specially neutrophils, and macrophage produce different cytokines and chemokines such as IL12, IL8, IL1, IL6, TNF $\alpha$ and INF $\gamma$ which contribute to the development of the inflammatory response by the direct activation of multiple apoptotic pathways $[20,21]$. DCs as main antigen presenting cell has central role in the development of the $\mathrm{T}$ cell responses in the lamina propria in the host susceptible to celiac disease and/or parasite infection [22]. We still do not have explanation for why some patients with a phenotype of severe mucosal damages have no much clinical symptoms? [23]. This might be related to other unknown non HLA genetic and/or environmental factors that need further assessments. The result of this study showed that most of the CD patients even positive for $T$. gondii carried HLA DQ2 haplotypes (>60\%) while most of the control were negative for both HLADQ2 and DQ8 haplotypes (> 55\%), but there was no correlation between anti-Toxoplasma IgG and HLA typing in either cases or controls.

Toxoplasma gondii is an intracellular parasite and following ingestion, oocysts are released into the GI tract and tachyzoites enter the host via the small bowel epithelium and then transform into bradyzoites [24].

Following oral ingestion T. gondii in animal model, the small intestine endothelial and epithelial cells produce different types of chemokines and cytokines and CD4+ $\mathrm{T}$ cell induce IFN- $\gamma$ and TNF- $\alpha$ production that will result in flat villi [25]. An experimental study showed a noticeable rise in the intestinal intraepithelial lymphocytes (IELs) population following infection with $T$. gondii similar to celiac disease (10). On the other hands, it may suggest that local microbiota play a critical role in the expansion of inflammatory response activities [26, 27] (Fig. 2).

A few studies have investigated the correlation between celiac disease and $T$. gondii infection [24, 28]. In a study by Plot and colleagues, prevalence of anti-Toxoplasma gondii antibodies was higher in control group compared to celiac group ( $25.9 \%$ vs $23.3 \%)$. Our results although is compatible with their findings but they did not investigate a correlation between $T$. gondii infection and mucosal abnormality as we done. In our previous study in 2011, of 827 pregnant women, 16 out of 27 (59\%) tTGA positive patients were seropositive for Toxoplasma gondii infection [24], but we did not evaluate the control group.

\section{Conclusions}

Finally, while the prevalence of anti- $T$. gondii IgG positivity is lower in $\mathrm{CD}$ than controls, our results indicate that T. gondii infection, increases the risk of severity of histology in celiac disease patients. It would be interesting to compare the intestinal mucosal abnormalities of non-coeliac patients presenting with high anti- T.gondii IgG with coeliac disease. Intestinal infections have been involved in triggering celiac disease and clearly Toxoplasma gondii may trigger the development of celiac disease in susceptible individuals.

\section{Additional file}

Additional file 1: Factors in combination may cause more severe tissue mucosal damage. TG = Toxoplasma gondii. (JPG 48 kb)

\section{Abbreviations \\ CD: Coeliac disease; DCs: Dendritic Cells; H\&E: Hematoxylin and Eosin; IELs: Intraepithelial lymphocytes; IgG: Immunoglobulin G; NCGS: non-coeliac gluten sensitivity; PCD: Potential celiac disease; T. gondii: Toxoplasma gondii; tTG: Tissue Transglutaminase}

\section{Acknowledgements}

We would like to thank Dr Hamid Mohaghegh and Dr. Mohamad Amin Pourhoseingholi for their kind support in the interpretation of data.

\section{Funding}

This study has been financially supported by Research Center of Gastroenterology and Liver disease (RCGLD), Shahid Beheshti University of Medical Sciences, Tehran, Iran. The funders had no role in study design, data collection and analysis, decision to publish, or preparation of the manuscript.

\section{Availability of data and materials}

The datasets used and analysed during the current study are available from the corresponding author on reasonable request.

\section{Authors' contributions}

MRN: study concept, drafting of the manuscript and acquisition of data, $\mathrm{SHH}$; statistical analysis and interpretation of data and drafting of the manuscript; HAA, UV, MRZ: critical revision of the manuscript for important intellectual content and material support; ASP: drafting of the manuscript, study supervision; KR: design, study concept drafting of the manuscript and study supervision. All authors have read and approved the manuscript prior to submission.

\section{Ethics approval and consent to participate}

Informed consent was obtained from each patient prior to study enrollment. The study was approved by ethics review board of Gastroenterology and Liver Diseases Research Center, Shahid Beheshti University of Medical Sciences, Tehran, Iran (IR.SBMU.RIGLD.1395.90).

\section{Competing interests}

The authors declare that they have no competing interests.

\section{Publisher's Note}

Springer Nature remains neutral with regard to jurisdictional claims in published maps and institutional affiliations.

\section{Author details}

${ }^{1}$ Celiac Disease Department, Gastroenterology and Liver Diseases Research Center, Research Institute for Gastroenterology and Liver Diseases, Shahid Beheshti University of Medical Sciences, Tehran, Iran. ${ }^{2}$ Skin Diseases and Leishmaniasis Research Center, Isfahan University of Medical sciences, Isfahan, Iran. ${ }^{3}$ Laboratory of Immunogenetics, Department of Medical Microbiology and Infection Control, Vrije Universiteit Medical Center (VUmc), 
Amsterdam, the Netherlands. ${ }^{4}$ Basic and Molecular Epidemiology of Gastrointestinal Disorders Research Center, Research institute for Gastroenterology and Liver Diseases, Shahid Beheshti University of Medical Sciences, Tehran, Iran. ${ }^{5}$ Department of Gastroenterology, Milton Keynes University Hospital, Milton Keynes, UK. ${ }^{6}$ Department of Medical and Surgica Sciences, University of Bologna, Bologna, Italy.

Received: 2 January 2018 Accepted: 8 May 2018

Published online: 18 May 2018

\section{References}

1. Rostami Nejad M, Rostami K, Pourhoseingholi MA, Nazemalhosseini Mojarad E, Habibi M, Dabiri H, Zali MR. A typical presentation is dominant and typical for coeliac disease. J Gastrointestin Liver Dis. 2009;18:285-91.

2. Rostami Nejad M, Hogg-Kollars S, Ishaq S, Rostami K. Subclinical celiac disease and gluten sensitivity. Gastroenterol Hepatol Bed Bench. 2011;4: 102-8.

3. Eiró N, González-Reyes S, González L, González LO, Altadill A, Andicoechea A, Fresno-Forcelledo MF, Rodrigo-Sáez L, Vizoso FJ. Duodenal expression of toll-like receptors and interleukins are increased in both children and adult celiac patients. Dig Dis Sci. 2012;57(9):2278-85. https://doi.org/10.1007/s10620-012-2184-6.

4. Rostami-Nejad M, Romanos J, Rostami K, Ganji A, Ehsani-Ardakani MJ, Bakhshipour AR, Zojaji H, Mohebbi SR, Zali MR, Wijmenga C. Allele and haplotype frequencies for HLA-DQ in Iranian celiac disease patients. World Gastroenterol. 2014;20(20):6302-8.

5. Khoshbaten M, Rostami Nejad M, Sharifi N, Fakhari A, Golamnejad M, Hashemi SH, Collin P, Rostami K. Celiac disease in patients with chronic psychiatric disorders. Gastroenterol Hepatol Bed Bench. 2012;5:90-3.

6. Khoshbaten M, Rostami Nejad M, Sharifi N, Majid Torabi, David Al Dulaimi, Kamran Rostami and Chris J Mulder. Assessing the prevalence of coeliac disease in patients with intellectual disabilities. Gastrointest Nurs 2010;8:32-36.

7. Whiteley P, Haracopos D, Knivsberg AM, Reichelt KL, Parlar S, Jacobsen J, Seim A, Pedersen L, Schondel M, Shattock P. The ScanBrit randomised, controlled, single-blind study of a gluten- and casein-free dietary intervention for children with autism spectrum disorders. Nutr Neurosci. 2010;13:87-100.

8. Rostami Nejad M, Rostami K, Emami M, Zali M, Malekzadeh R. Epidemiology of celiac disease in Iran: a review. Middle East J Dig Dis. 2011;3:5-12.

9. Chardes T, Buzoni-Gatel D, Lepage A, Bernard F, Bout D. Toxoplasma gondii oral infection induces specific cytotoxic CD8 alpha/beta+ Thy-1+ gut intraepithelial lymphocytes, lytic for parasite-infected enterocytes. J Immunol. 1994;153:4596-603.

10. Kasper L, Courret N, Darche S, Luangsay S, Mennechet F, Minns L, Rachinel $\mathrm{N}$, Ronet C, Buzoni-Gatel D. Toxoplasma gondii and mucosal immunity. Int J Parasitol. 2004;34:401-9.

11. Liesenfeld O, Nguyen TA, Pharke C, Suzuki Y. Importance of gender and sex hormones in regulation of susceptibility of the small intestine to peroral infection with toxoplasma gondii tissue cysts. J Parasitol. 2001;87:1491-3.

12. Marsh MN, Johnson MW, Rostami K. Rebutting Oberhuber- Again. Gastroenterol Hepatol Bed Bench. 2015;8:303-5.

13. Rostami-Nejad M, Villanacci V, Hogg-Kollars S, Volta U, Manenti S, Reza-Zali M, Caio G, Giovenali P, Barakauskiene A, Kazenaite E, Becheanu G, Diculescu M, Pellegrino S, Magazzù G, Casella G, Di-Bella C, Decarli N, Biancalani M, Bassotti G, Rostami K. Endoscopic and histological pitfalls in the diagnosis of celiac disease: a multicentre study assessing the current practice. Rev Esp Enferm Dig. 2013;105:326-33.

14. Ludvigsson JF, Agreus L, Ciacci C, Crowe SE, Geller MG, Green PH, Hill I, Hungin AP, Koletzko S, Koltai T, Lundin KE, Mearin ML, Murray JA, Reilly N, Walker MM, Sanders DS, Shamir R, Troncone R, Husby S. Transition from childhood to adulthood in coeliac disease: the Prague consensus report. Gut. 2016;65:1242-51.

15. Mashayekhi K, Rostami-Nejad M, Azimzadeh P, Amani D, Kazemian S, Derakhshani S, Hasanzadeh H, Zali MR. Setup of SYBR freen real-time PCR method to detect the HLA-DQ alleles in patients with celiac disease. Koomesh. 2015;16:527-35.

16. Maya R, Gershwin ME, Shoenfeld Y. Hepatitis B virus (HBV) and autoimmune disease. Clin Rev Allergy Immunol. 2008;34:85-102.

17. Rostami Nejad M, Ishaq S, Al Dulaimi D, Al Dulaimi D, Zali MR, Rostami K. The role of infectious mediators and gut microbiome in the pathogenesis of celiac disease. Arch Iran Med. 2015;18:244-9.
18. Rostami-Nejad M, Rostami K, Sanaei M, Mohebbi SR, Al-Dulaimi D, Nazemalhosseini-Mojarad E, Collin P, Mulder CJ, Zali MR. Rotavirus and coeliac autoimmunity among adults with non-specific gastrointestinal symptoms. Saudi Med J. 2010;31(8):891-4

19. Carroccio A, Cavataio F, Montalto G, Paparo F, Troncone R, lacono G. Treatment of giardiasis reverses "active" coeliac disease to "latent" coeliac disease. Eur J Gastroenterol Hepatol. 2001;13:1101-5.

20. Bennouna S, Sukhumavasi W, Denkers EY. Toxoplasma gondii inhibits tolllike receptor 4 ligand-induced mobilization of intracellular tumor necrosis factor alpha to the surface of mouse peritoneal neutrophils. Infect Immun 2006;74:4274-81.

21. Denkers EY, Del Rio L, Bennouna S. Neutrophil production of IL-12 and other cytokines during microbial infection. Chem Immunol Allergy. 2003;83: $95-114$

22. Belkaid $Y$, Bouladoux $N$, Hand TW. Effector and memory $T$ cell responses to commensal bacteria. Trends Immunol. 2013;34:299-306.

23. Rostami K, Aldulaimi D, Holmes G, Johnson MW, Robert M, Srivastava A, Fléjou JF, Sanders DS, Volta U, Derakhshan MH, Going JJ, Becheanu G, Catassi C, Danciu M, Materacki L, Ghafarzadegan K, Ishaq S, Rostami-Nejad M, Peña AS, Bassotti G, Marsh MN, Villanacci V. Microscopic enteritis: Bucharest consensus. World J Gastroenterol. 2015;21:2593-604.

24. Rostami Nejad M, Rostami K, Cheraghipour K, Nazemalhosseini Mojarad E, Volta U, Al Dulaimi D, Zali MR. Celiac disease increases the risk of toxoplasma gondii infection in a large cohort of pregnant women. Am J Gastroenterol. 2011;106:548-9.

25. Mennechet FJ, Kasper LH, Rachinel N, Li W, Vandewalle A, Buzoni-Gatel D. Lamina propria CD4+ T lymphocytes synergize with murine intestinal epithelial cells to enhance proinflammatory response against an intracellular pathogen. J Immunol. 2002;168:2988-96.

26. Buzoni-Gatel D, Schulthess J, Menard LC, Kasper LH. Mucosal defences against orally acquired protozoan parasites, emphasis on toxoplasma gondii infections. Cell Microbiol. 2006;8:535-44.

27. Buzoni-Gatel D, Debbabi H, Moretto M, Dimier-Poisson IH, Lepage AC, Bout DT, Kasper LH. Intraepithelial lymphocytes traffic to the intestine and enhance resistance to toxoplasma gondii oral infection. J Immunol. 1999;162:5846-52

28. Plot L, Amital H, Barzilai O, Ram M, Bizzaro N, Shoenfeld Y. Infections may have a protective role in the etiopathogenesis of celiac disease. Ann N Y Acad Sci. 2009;1173:670-4

\section{Ready to submit your research? Choose BMC and benefit from:}

- fast, convenient online submission

- thorough peer review by experienced researchers in your field

- rapid publication on acceptance

- support for research data, including large and complex data types

- gold Open Access which fosters wider collaboration and increased citations

- maximum visibility for your research: over $100 \mathrm{M}$ website views per year

At BMC, research is always in progress.

Learn more biomedcentral.com/submissions 